\title{
The flightless I protein interacts with RNA-binding proteins and is involved in the genome-wide mRNA post-transcriptional regulation in lung carcinoma cells
}

\author{
CUIHUA WANG ${ }^{*}$, KEZHI CHEN ${ }^{*}$, SHENGYOU LIAO, WEI GU, XINLEI LIAN, JING ZHANG, \\ XUEJUAN GAO, XIAOHUI LIU, TONG WANG, QING-YU HE, GONG ZHANG and LANGXIA LIU \\ Key Laboratory of Functional Protein Research of Guangdong Higher Education Institutes, \\ Institute of Life and Health Engineering, Jinan University, Guangzhou, Guangdong 510632, P.R. China
}

Received February 28, 2017; Accepted April 24, 2017

DOI: 10.3892/ijo.2017.3995

\begin{abstract}
The flightless I protein (FLII) belongs to the gelsolin family. Its function has been associated with actin remodeling, embryonic development, wound repair, and more recently with cancer. The structure of FLII is characterized by the N-terminal leucine-rich repeats (LRR) and C-terminal gesolin related repeated units that are both protein-protein interaction domains, suggesting that FLII may exert its function by interaction with other proteins. Therefore, systematic study of protein interactions of FLII in cells is important for the understanding of FLII functions. In this study, we found that FLII was downregulated in lung carcinoma cell lines H1299 and A549 as compared with normal HBE (human bronchial epithelial) cell line. The investigation of FLII interactome in H1299 cells revealed that 74 of the total 132 putative FLII interactors are involved in RNA post-transcriptional modification and trafficking. Furthermore, by using high-throughput transcriptome and translatome sequencing combined with cell fractionation, we showed that the overexpression or knockdown of FLII impacts on the overall nuclear export, and translation of mRNAs. IPA analysis revealed that the majority of these target mRNAs encode the proteins
\end{abstract}

Correspondence to: Prof. Langxia Liu or Prof. Gong Zhang, Key Laboratory of Functional Protein Research of Guangdong Higher Education Institutes, Institute of Life and Health Engineering, Jinan University, Guangzhou, Guangdong 510632, P.R. China

E-mail: langxialiu@gmail.com; tliulx@jnu.edu.cn

E-mail: zhanggong@jnu.edu.cn

*Contributed equally

Abbreviations: FLII, flightless I; LRR, leucine-rich repeats; HBE, human bronchial epithelial; IPA, ingenuity pathway analysis; NSCLC, non-small cell lung cancer; RNC, ribosome-nascent chain complex; NPC, nuclear pore complex; rpkM, reads per kilobase per million reads; EEF2, eukaryotic elongation factor 2

Key words: flightless I, interactome, lung cancer, RNA-binding protein, RNA post-transcriptional regulation whose functions are reminiscent of those previously reported for FLII, suggesting that the post-transcriptional regulation of mRNA might be a major mechanism of action for FLII.

\section{Introduction}

Lung cancer has become the most common cause of cancer-related mortality and a serious public health concern worldwide. In China, the lung cancer-related mortality rate has been multiplied by 4.6 in the past 3 decades. It will reach the alarming 1 million per year by 2025 , as estimated by WHO (1). Among all lung cancers, $85 \%$ are NSCLC (non-small cell lung cancer). At the moment of diagnosis, most of NSCLC patients present with locally advanced or metastatic disease, when the surgical intervention is no longer feasible despite its high success rate if applied earlier. For these patients, systemic chemotherapy with concurrent radiotherapy remains a necessary option for cure. For this reason, the identification of the proteins playing key roles in the physiopathology of NSCLC that could be potential targets for the chemotherapy reveals to be important and emergent.

The flightless I protein (FLII) belongs to the gelsolin family of actin severing proteins. At the time of its discovery, Drosophila melanogaster FLII was shown to play an important role in the embryonic development. The following studies on mammalian FLII demonstrated that this protein is also involved in the regulation of wound repair, skin barrier development, the recovery after blistering and regulation of immune response (2-9). Recently, studies have also demonstrated that FLII is involved in colorectal cancer, hepatocellular and prostate cancer (10-13). Notably, a role of tumor suppressor in prostate cancer has been attributed to this protein (14).

Despite the previous attempts of identifying the FLII interactome in the cells using yeast-two hybrid system $(15,16)$, the systemic picture of protein interaction network of FLII still remains elusive. In this study, by combining co-immunoprecipitation and mass spectrometry analysis, we have identified 132 putative FLII interactors in lung adenocarcinoma cancer H1299 cells, and found that more than a half of them are proteins involved in RNA post-transcriptional regulation and protein biosynthesis. By combining cell fractionation, 
mRNA-seq and translating mRNA sequencing (RNC-seq), we evaluated the function of FLII on the transcription, nuclear export and translation of mRNAs. We demonstrated that FLII affects the overall nuclear export and translation of mRNAs.

\section{Materials and methods}

Antibodies. Rabbit polyclonal anti-FLII (sc-30046) antibody, mouse polyclonal anti-HNRNPQ (sc-56703) antibody, goat polyclonal anti-TIAL1 (sc-1749) antibody mouse monoclonal anti-actin (sc-47778), mouse monoclonal anti-NUP88 (sc-136009) antibody, peroxidase-conjugated AffiniPure goat anti-Mouse IgG $(\mathrm{H}+\mathrm{L})$, peroxidase-conjugated AffiniPure goat anti-rabbit IgG $(\mathrm{H}+\mathrm{L})$, rabbit anti-goat IgG $(\mathrm{H}+\mathrm{L})$-HRP (sc-2768) were purchased from Santa Cruz Biotechnology (Santa Cruz, CA, USA).

Cell culture. Human H1299 and HBE cells (Cell Resource Center, Institute of Life Science Chinese Academy of Sciences, Shanghai, China) were cultured in Dulbecco's modified Eagle's medium (DMEM, Gibco BRL, Grand island, NY, USA) supplemented with $10 \%$ fetal bovine serum (PAA Laboratories, Weike Biochemical Reagent, Shanghai, China), $1 \%$ penicillin/streptomycin (Genom, Hangzhou, China) at $37^{\circ} \mathrm{C}$ in a humidified atmosphere containing $5 \% \mathrm{CO}_{2}$.

Plasmid constructions. The pot-b7-FLII plasmid containing the cDNA of the human FLII was obtained from Yingrun Biotechnologies Inc. (Changsha, China). The cDNA fragment encoding FLII was PCR-amplified and inserted into pCMVN-FLAG-vector using the EcoRV and SpeI restriction sites. A primer pair (upstream: 5'-ATTGATATCATGGAGGCCACC GGGGTGCTG-3' and downstream: 5'-ATAACTAGTTTAG GCCAGGGCCTTGCAGAA-3') was designed based on NCBI GenBank NP_002009.1. All the plasmids were accuratly confirmed by DNA sequencing.

Transfections and immunoprecipitation of FLII. Cells were transfected with either empty pCMV-N-Flag or pCMV-NFlag-FLII vectors using Lipofectamine 2000 (Invitrogen, Carlsbad, CA, USA). At $48 \mathrm{~h}$ after transfection, cells were lysed using EBC lysis buffer. Total soluble extract $(1 \mathrm{mg})$ was incubated with anti-Flag antibody overnight at $4^{\circ} \mathrm{C}$. Protein A/G-Sepharose was added and incubated for $4 \mathrm{~h}$ at $4^{\circ} \mathrm{C}$. After washing, the precipitated proteins were eluted and separated using SDS-PAGE. The gel was stained with Silver nitrate after migration, and gel lanes were subsequently cut, destained, reduced, alkylated and digested with gold-trypsin at $37^{\circ} \mathrm{C}$ overnight. The tryptic peptides were extracted, and the peptide mixtures were concentrated by SpeedVac centrifuge to dryness and re-dissolved with $2 \% \mathrm{ACN}$ in $0.1 \%$ formic acid before LC-MS/MS analysis. For the confirmation of the presence of Flag-FLII in the immune-complexes, the immunoprecipitates were washed with immunoprecipitation assay buffer three times, and subjected to western blot analysis using anti-Flag antibody.

$M S$ analysis. The peptide mixtures were analyzed by reversephase liquid chromatography coupled with LTQ-Orbitrap mass spectrometer (Thermo Electron, Bremen, Germany) as previously described with minor modification (17). Briefly, the peptide mixtures were firstly loaded on a C18 reverse-phase column (100-mm i.d., 10-cm long, 5-mm resin from Michrom Bioresources, Auburn, CA, USA) using an auto sampler. The peptide mixtures were eluted with $0-40 \%$ gradient buffer solution (Buffer A, $0.1 \%$ formic acid, and 5\% ACN; Buffer B, $0.1 \%$ formic acid and $95 \% \mathrm{ACN}$ ) over $180 \mathrm{~min}$. The eluate was then analyzed online in the LTQ-Orbitrap mass spectrometer operated in a data-dependent mode with capillary temperature of $2001 \mathrm{C}$ and spray voltage of $1.80 \mathrm{kV}$. A full MS scan with $\mathrm{m} / \mathrm{z} 350-1800$ was carried out in the Orbitrap at resolution $\mathrm{r} 5100,000$ at $\mathrm{m} / \mathrm{z} 400$, and followed by five MS2 scans in the LTQ with Dynamic Exclusion setting: 2 repeat counts with repeat duration of $30 \mathrm{sec}$ and exclusion duration of $90 \mathrm{sec}$. MS3 was further performed if an ion had a neutral loss of $-98.00,-58.00,-49.00,-38.67,-32.67$ or $-24.50 \mathrm{Da}$ in the MS2 and the ion was one of the top five most intense ions in the MS2. Conditions with 35\% normalized collision energy, activation q of 0.25 and activation time of $30 \mathrm{msec}$ were applied for MS2 and MS3 acquisitions.

Stable FLII knockdown in HBE cells. Lentiviral shRNA vectors (GenePharma, Shanghai, China) targeting human FLII were utilized for stable knockdown in HBE cells. Procedures were conducted according to the manufacturer's protocol. The FLII siRNA sense sequence (5'-GGGCTAGACATCTACG TAT-3') and Scramble siRNA sense sequence (5'-TTCTCC GAACGTGTCACGTTTC-3') were used to design the shRNA that were inserted into PGLV3/H1/GFP+ pur Vector under H1 promoter. Cells resistant to puromycin $(1.5 \mu \mathrm{g} / \mathrm{ml})$ were selected and passaged for further study.

Cell fractionation. Six million human H1299 or HBE cells were resuspended in $500 \mu \mathrm{l}$ ice cold Extraction Buffer $(10 \mathrm{mM}$ Tris- $\mathrm{HCl}, 10 \mathrm{mMKCl}, 5 \mathrm{mM} \mathrm{MgCl}_{2}$, protease and phosphatase inhibitors, RNase inhibitor, VRC) and incubated on ice for $10 \mathrm{~min}, 500 \mu 10.6 \%$ Triton/Extraction Buffer was then added, followed by $10 \mathrm{sec}$ of vortex, and incubation on ice for further $10 \mathrm{~min}$, then vortex for $10 \mathrm{sec}$ again. Lysate was then subjected to vertical centrifugation for $5 \mathrm{~min}$ at $600 \mathrm{x} \mathrm{g}$ speed at RT. Supernatant corresponding to the cytoplasmic fraction was transferred into a new tube. The pellet corresponding to the cell nucleus was subsequently resuspended in $1 \mathrm{ml} 0.6 \%$ Triton Extraction Buffer by pipetting 10 times, incubated on ice for 5 min, followed by vertical centrifugation for $5 \mathrm{~min}$ at $600 \mathrm{x} \mathrm{g}$ speed at RT, The supernatant corresponded to nuclear extract was then collected. This experiment was repeated thrice, and the cytoplasmic or nuclear extract resulted from the three experiments were pooled together, and served for the RNA extraction using Trizol reagent (Invitrogen).

Ribosome-nascent chain complex (RNC) extraction. The RNC extraction was performed as described by Esposito et al (18) with modifications. In brief, cells were pre-treated with $100 \mathrm{mg} / \mathrm{ml}$ cycloheximide for $15 \mathrm{~min}$, followed by pre-chilled phosphate buffered saline washes and addition of $2 \mathrm{ml}$ cell lysis buffer [1\% Triton X-100 in ribosome buffer (RB buffer) $20 \mathrm{mM}$ HEPES-KOH (pH 7.4), $15 \mathrm{mM} \mathrm{MgCl} 2,200 \mathrm{mMKCl}$, $100 \mathrm{mg} / \mathrm{ml}$ cycloheximide and $2 \mathrm{mM}$ dithiothreitol]. After 
A

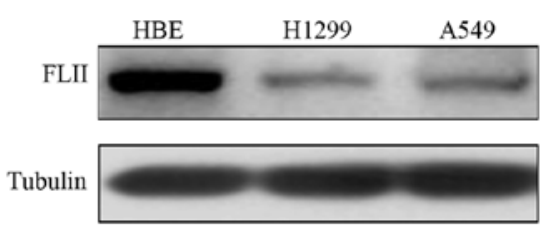

C

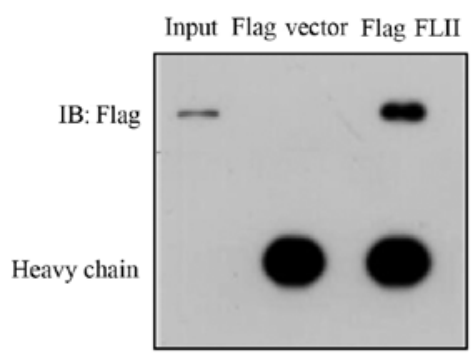

D
B
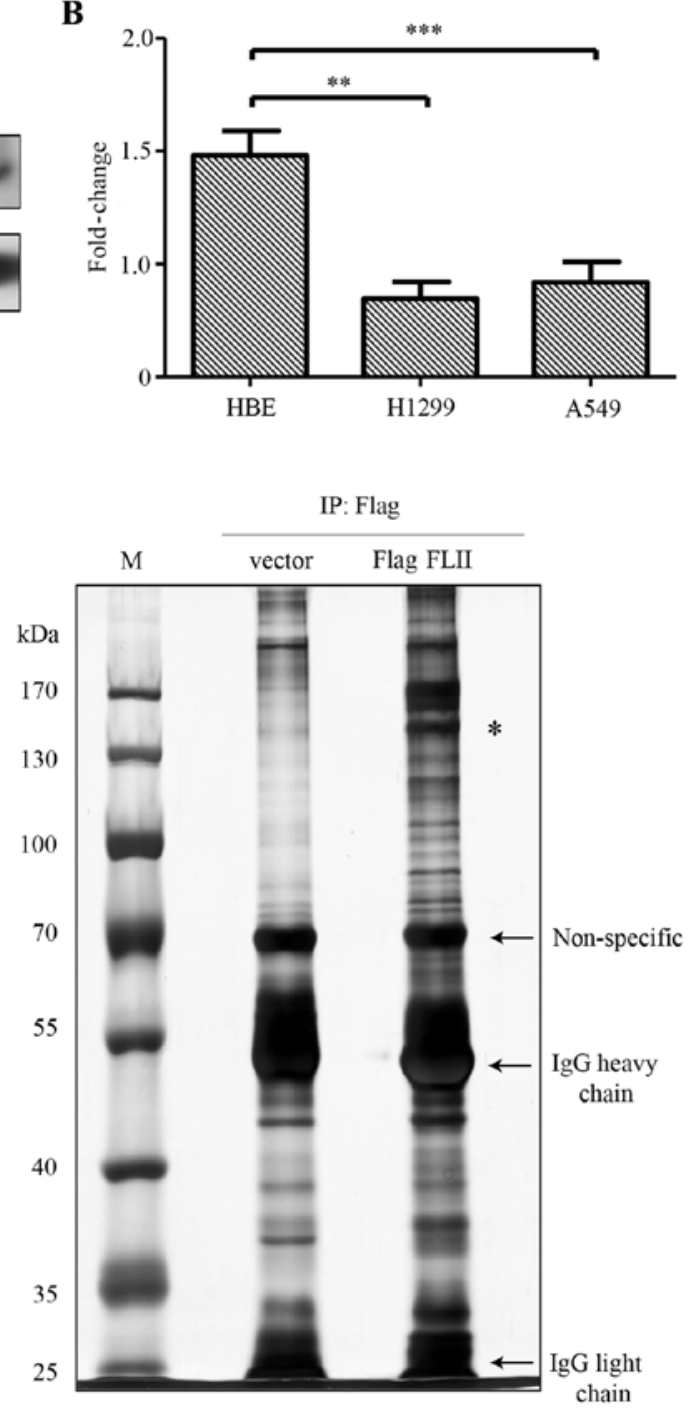

Figure 1. Identification of FLII interactome in H1299 lung carcinoma cells. (A) FLII expression in HBE, H1299 and A549 cells determined by western blotting. (B) Quantification of the FLII protein bands shown in (A) by using ImageJ. Data are from five independent experiments; Error bars indicate s.d. ${ }^{* *} \mathrm{P}<0.05$, ${ }_{* * * *}^{*} \mathrm{P}<0.01$, by Student's t-test. (C) H1299 cells transfected with the empty Flag vector or the Flag-tagged FLII was subjected to immunoprecipitation with anti-Flag antibody. The presence of the immunoprecipitated FLII was revealed by western blotting using the anti-Flag antibody with $1 / 10$ of the immunoprecipitates. (D) The remaining immunoprecipitates from (C) were run in SDS-PAGE and colored by silver staining. The protein band possibly corresponds to FLII is denoted by the asterisks. The heavy and light chains of the anti-Flag antibody, together with the $70 \mathrm{kDa}$ non-specific protein band are also indicated.

30-min ice-bath, cell lysates were scraped and transferred to pre-chilled $1.5 \mathrm{ml}$ tubes. Cell debris was removed by centrifuging at $13,200 \mathrm{x}$ g for $10 \mathrm{~min}$ at $4^{\circ} \mathrm{C}$. Supernatants were transferred on the surface of $20 \mathrm{ml}$ of sucrose buffer (30\% sucrose in RB buffer). RNCs were pelleted after ultracentrifugation at $185,000 \mathrm{x}$ g for $5 \mathrm{~h}$ at $4^{\circ} \mathrm{C}$. RNC-RNA was purified using TRIzol method.

Next-generation sequencing and sequence analysis. Total RNA and RNC-RNA of human H1299 and HBE cells were extracted as previously described (18). Equal amounts of total mRNA or RNC-mRNA isolated from three independent cultures were pooled and reverse-transcribed into cDNA. The yielded cDNA library was then constructed and subjected to RNA-seq analysis using Illumina HiSeq ${ }^{\mathrm{TM}}$ 2000. The sequencing data sets are deposited in Gene Expression Omnibus database under the accession number of GSE92979. Reads were mapped to human mRNA reference sequence (RefSeq) for GRCh37/hg19 in UCSC genome browser (downloaded from http://hgdownload.cse.ucsc.edu/downloads, accessed January 21, 2013) using FANSe2 mapping algorithm with the options -L78 -S8 -I0 -E9 -B1. The reads mapped to splice variants of one gene were summed. The mRNA abundance was normalized using both rpkM (reads per kilobase per million reads). Differential expression was evaluated using edgeR since it outperforms the other mainstream differential expression models (19). Genes with $>10$ mapped reads were considered as quantified genes. The cytoplasm/nucleus distribution of each given mRNA has been quantified in all experimental groups of cells, and the variation of such distribution between the FLII knocked down HBE or the FLII overexpressing H1299 cells and their respective control cells were calculated. Where Flag-FLII and Flag-Vector refer to H1299 cells transfected with Flag-FLII and Flag vector; shRNA-FLII and shRNA-Ctrl refer to HBE cells expressing the shRNA against FLII and the control shRNA. 'C' for cytoplasmic, and ' $N$ ' for nuclear. 
A

Flag

Flag
IB: Flag

IB: Importin $\beta$

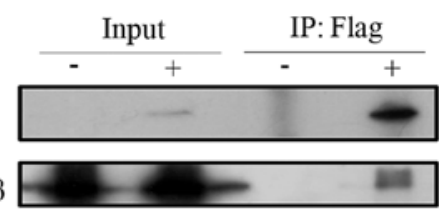

Input

IgG

B

Flag

IB: Flag

IB: HnRNPQ

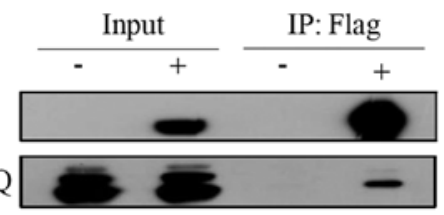

IB: FLII

IB: FLII

IB: Importin $\beta$

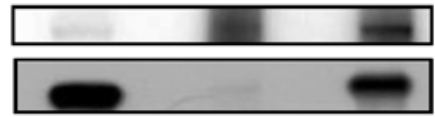

IB: Nup88

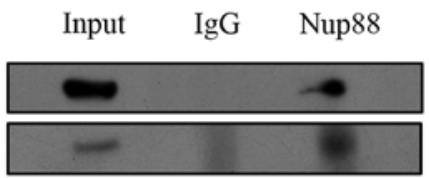

C

Flag

IB: Flag

IB: EEF2

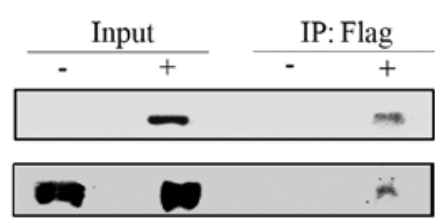

Figure 2. Validation of interactions between FLII and the representative interacting partners. (A) H1299 cells transfected with the Flag-tagged FLII was subjected to immunoprecipitation (IP) with Flag antibody and the interaction of endogenous importin $\beta$ and overexpressed FLII was determined by western blotting (WB) with indicated antibodies (upper panels). The interaction of endogenous importin $\beta$ and FLII was confirmed by co-IP with the negative control IgG and importin $\beta$ antibodies (lower panels). (B) Co-immunoprecipitation of Flag-FLII with the endogenous hnRNPQ (upper panels) in H1299 cells transfected with Flag-FLII, and co-immunoprecipitation of endogenous FLII and Nup88 in H1299 cells (lower panels) by using appropriate antibodies as indicated. (C) H1299 cells were transfected with the Flag-tagged FLII then subjected to co-immunoprecipitation (IP) with Flag antibody for the interaction between endogenous EEF2 and overexpressed FLII. WB were performed with the immunoprecipitates using the indicated antibodies.

Reverse transcription and PCR. Total RNA or RNC-RNA, isolated from both $\mathrm{H} 1299$ and HBE cells, were reverse transcribed to cDNA with poly-dT primer using Reverse Transcriptase XL (AMV) (Takara, Foster City, CA, USA), by following the manufacturer's instructions. The quantitative real-time PCR (qPCR) was then performed with gene-specific primers and the SsoFast ${ }^{\mathrm{TM}}$ EvaGreen Supermix (Bio-Rad, Hercules, CA, USA) on a Bio-Rad MiniOpticon real-time PCR system (Bio-Rad) by following the manufacturer's instructions. The specificity of the primers was verified by both in Silico Computation (NCBI Primer-BLAST) and melting curve measurement after the qPCR amplification.

Computational analyses. Protein interaction network was built by using STRING-DB (string-db.org) with default settings (all interaction sources selected, "medium confidence (0.400)' for minimum required interaction score, and 'query protein only' for max number of interactors to show). Ingenuity pathway analysis (IPA) was performed as described previously with minor modifications. Briefly, target proteins (DEPs) were uploaded into www.ingenuity.com (Ingenuity Systems, Inc., Redwood City, CA, USA). Core analyses were performed to identify top canonical pathways, bioprocesses and effects on functions.

Cell migration and invasion. In vitro migration and invasion assays were performed using Boyden chambers as previously described with minor modifications (20). In brief, for migration assays, cells transfected with pCMV-N-Flag-FLII or pCMV-N-Flag plasmid were resuspended in serum-free medium and seeded in the upper transwell chamber $(8.0 \mathrm{mM}$ pore size, Corning), and medium supplemented with $10 \%$ FCS was added to the bottom chamber, and cultured under regular conditions for $6 \mathrm{~h}$, cells on the upper surface of filters were then removed and those on the under-surface were stained with 5\% crystal violet. Images were captured from each membrane and the number of migrated cells was counted under a microscope. For invasion assays, similar transwell chambers coated with Matrigel ( $8.0 \mathrm{mM}$ pore size, Chemicon) were used to analyze the invasive potential regulated by FLII.

Statistics. The Spearman correlation coefficients were calculated to determine bivariate relationships. The regression, data distribution and standard deviations were calculated by using MATLAB R2012a software package (MathWorks, Natick, MA, USA). Data are shown as mean \pm standard deviation. Statistical difference was accepted at $\mathrm{P}<0.001$.

\section{Results}

FLII is downregulated in lung carcinoma cells. In order to assess the possible role of FLII in the physiopathology of NSCLC, we firstly examined its expression pattern in two lung adenocarcinoma epithelial cell lines, namely H1299 and A549 cell lines. Of note, we observed that FLII was significantly downregulated in A549 and H1299 lung carcinoma cells, as compared with the human bronchial epithelial (HBE) cells (Fig. 1A and B). This result is consistent with the recent study reporting that FLII is a tumor suppressor (14).

Identification of FLII interactome in H1299 lung carcinoma cells. We then tried to identify the possible interactors of FLII in H1299 cells. Immunoprecipitation experiment was carried out using anti-Flag antibody in Flag-FLII transfected H1299 cells as described in Materials and methods. The immunoprecipitation of Flag-FLII was then confirmed by western blotting using an anti-Flag antibody with one tenth of the immunoprecipitates from the Flag-FLII transfected and the empty Flag vector transfected cells (Fig. 1C). The remaining immunoprecipitates were run on an SDS-PAGE gel that was 
A

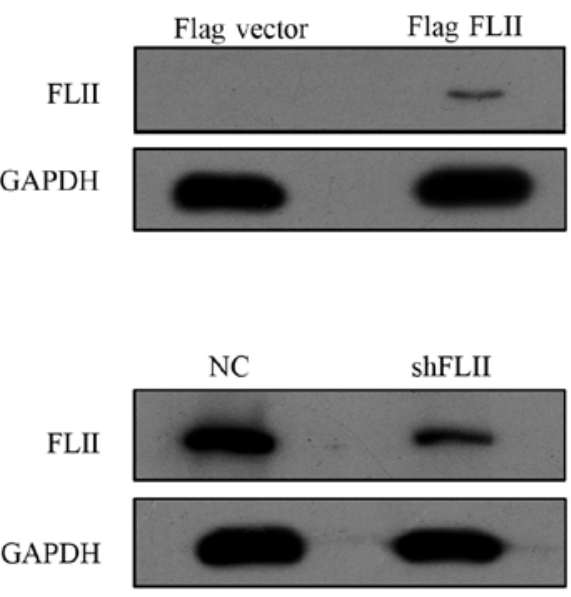

B
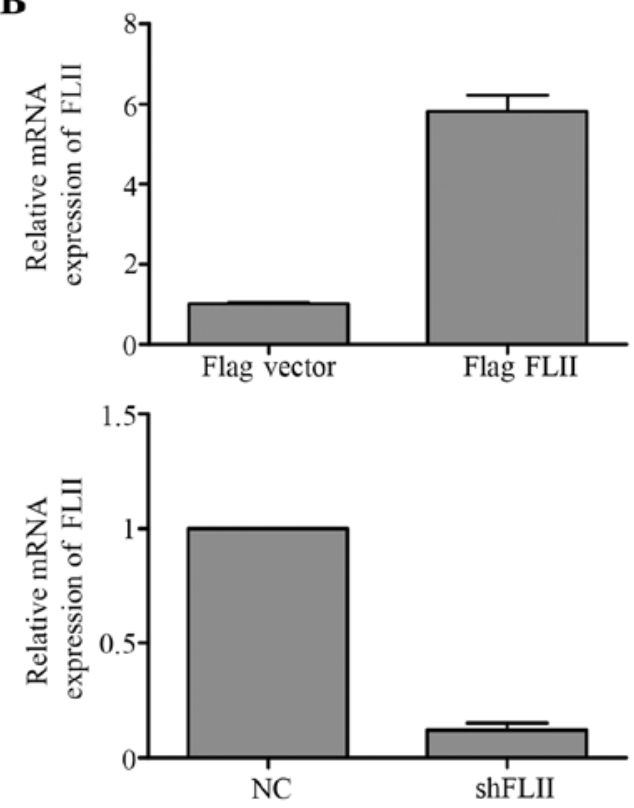

C
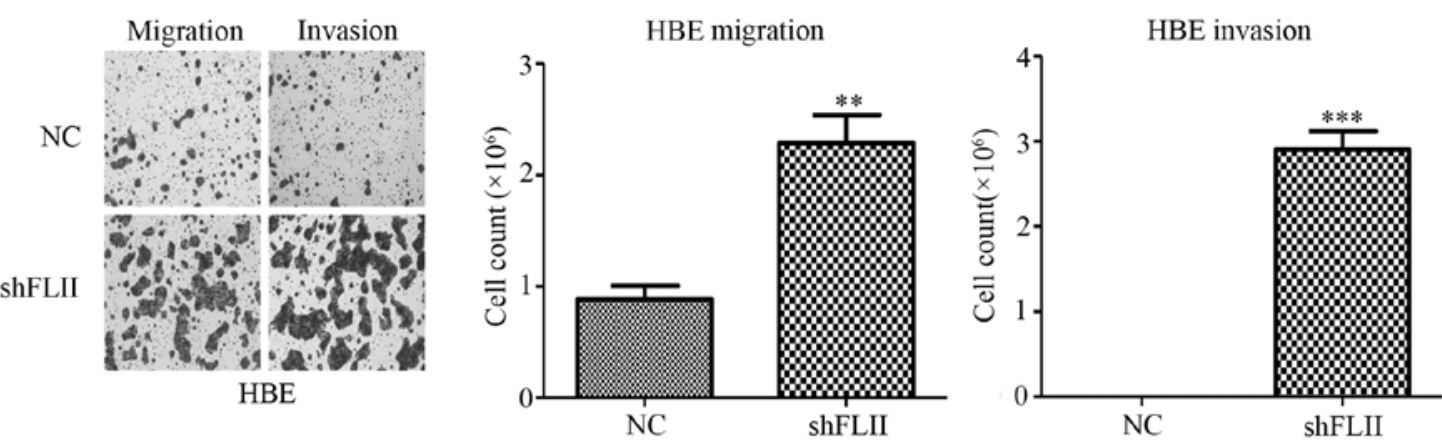

D

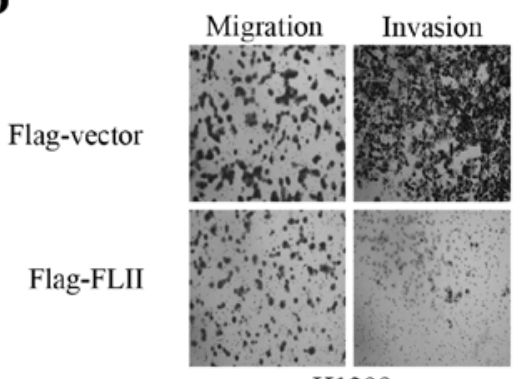

H1299
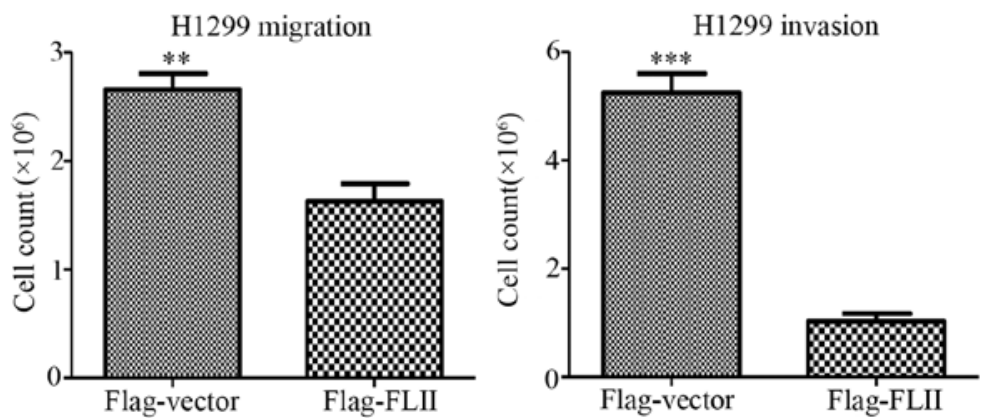

Figure 3. Effectiveness of FLII overexpression or knockdown in the corresponding HBE or H1299 cells. (A) H1299 cells transfected with Flag-FLII and HBE cells with stable lentiviral-mediated FLII knockdown were analyzed by western blotting with anti-Flag (upper panels) or anti-FLII antibody (lower panels). H1299 cells transfected by the empty Flag vector, or HBE cells infected by a control virus was respectively used as negative controls. (B) mRNA levels of FLII in Flag-FLII overexpressing H1299 and FLII knocked down HBE cells are determined by qRT-PCR with appropriate primers. Data are expressed by setting the relative value of the control cells to 1. Results shown represent the mean value of three independent experiments. (C) Boyden's chamber assays were performed to assess the impact of FLII knockdown on the migrating and invasive abilities of HBE cells as described. The migrated cells (images shown in the left panels) were counted, and the results represent the mean values of three independent experiments. Error bars indicate s.d. ${ }^{* *} \mathrm{P}<0.05,{ }^{* * * *} \mathrm{P}<0.01$, by $\mathrm{Student} s$ t-test. (D) Analyses similar to (C) were performed with Flag-FLII overexpressing H1299 cells.

subsequently silver-stained (Fig. 1D). The protein bands of both Flag-FLII transfected and the negative control lanes were extracted for tryptic in-gel digestion. Digested peptides were then subjected to LC-MS/MS analysis for protein identification. Proteins (263) were identified in Flag-FLII transfected lane. One hundred and thirty of them were also found in the negative control lane, thus considered to be unspecific and excluded from the candidates for further analyses. Among the 133 remaining proteins, we found FLII protein with 15 unique peptides specifically counted, further confirming the effectiveness of the immunoprecipitation. The other 132 proteins were considered to be the putative FLII-interacting partners. 
$\mathbf{A}$

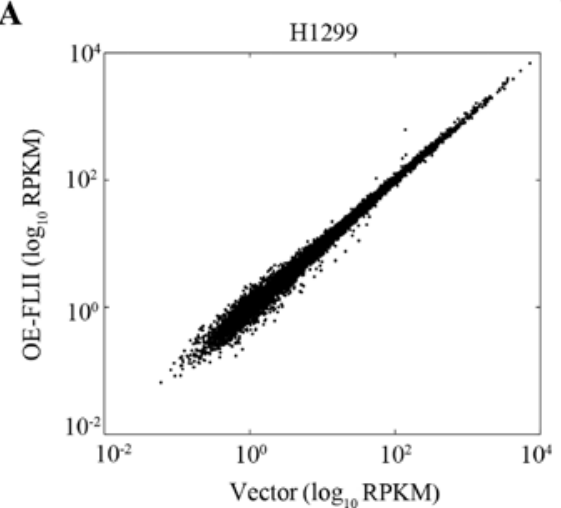

C

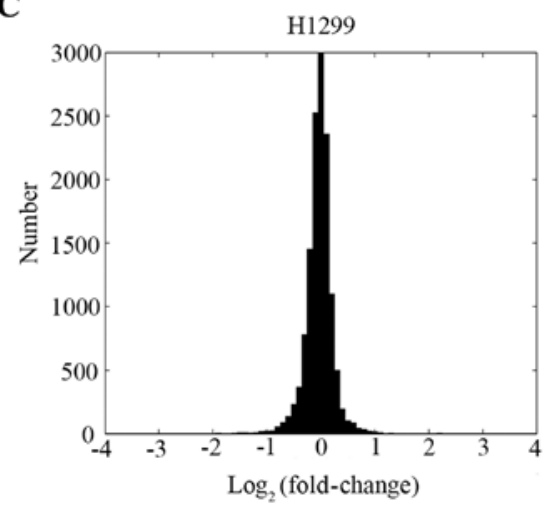

$\mathbf{E}$

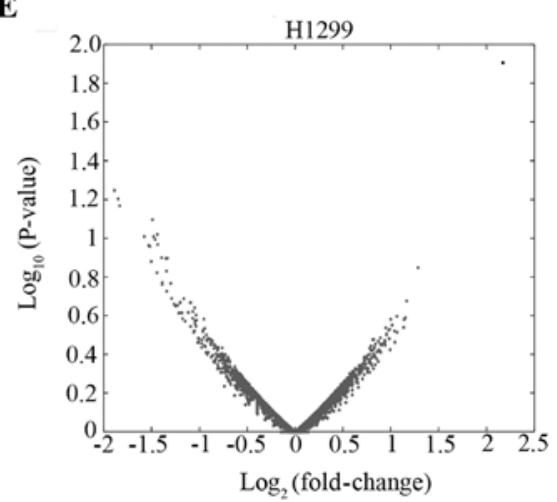

B

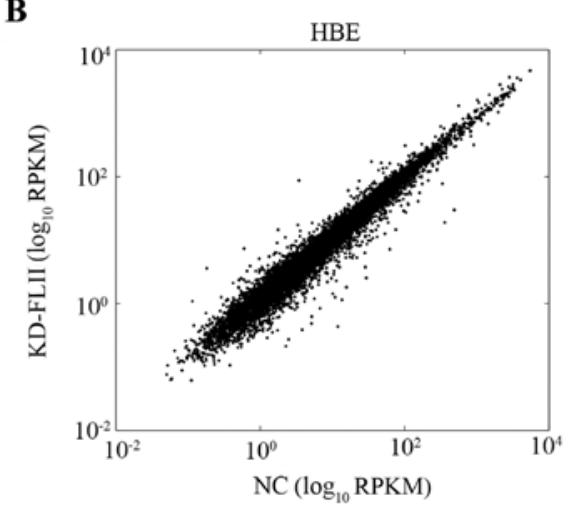

D

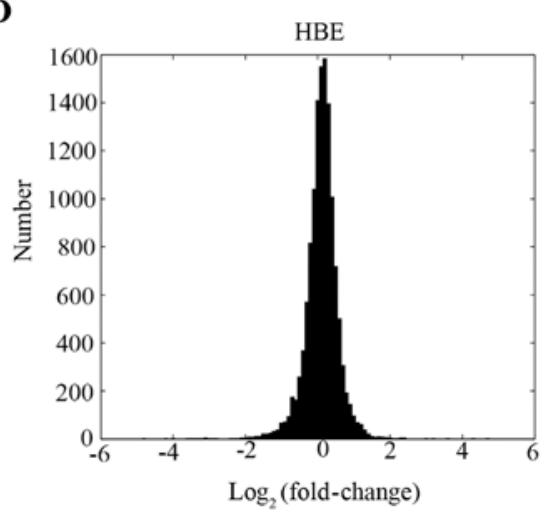

$\mathbf{F}$

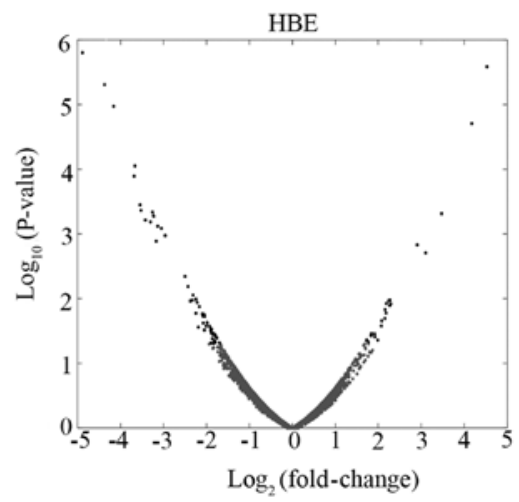

Figure 4. Assessment of FLII functions in RNA transcription by high throughput sequencing. The variation of total mRNA levels in FLII-overexpressing H1299 cells (A), or FLII knocked down HBE cells (B), and the corresponding distributions in fold changes (C and D). (E and F) EdgeR analysis for the differential mRNA levels caused by FLII-overexpression or FLII knockdown in the corresponding cells as indicated. Significantly altered genes are denoted by the black dots while the others are gray dots.

Validation of interactions between FLII and the representative interacting partner. In order to confirm the interactions of FLII with its putative partners identified by mass spectrometry, we carried out experiments to confirm the co-immunoprecipitation of FLII with its several representative partners using corresponding specific antibodies, as shown in Fig. 2 for Importin $\beta$ (karyopherin $\beta$ ), Nup88, Syncrip and EEF2. Due to the variable quality or suitability of the antibodies for co-immunoprecipitation assays, the experiments were performed either with endogenous or overexpressed Flag-tagged FLII as indicated when appropriate. Fig. 2A shows the interaction of the overexpressed FLII with Importin $\beta$ using the anti-Flag antibody in Flag-FLII transfected H1299 cells (upper panel) and the interaction between endogenous FLII and Importin $\beta$ in H1299 cells (lower panel). The interaction of FLII with Syncrip and Nup88 has been confirmed, respectively, by using the anti-Flag antibody in Flag-FLII transfected H1299 cells (Fig. 2B, upper panel) and by using the Nup88 antibody in H1299 cells (Fig. 2B, lower panel). As shown in Fig. 2C, we confirmed the interaction between FLII and EEF2 in Flag-FLII transfected H1299 cells. Among these confirmed representative partners, Importin $\beta$ and Nup88 are, respectively, important nuclear transport receptor and component of the nuclear pore complex (NPC) involved in the nucleocytoplasmic transport. Particularly, both of them have been reported to be involved in the nuclear export of mRNA, protein and 60S ribosomal complex (21-23). Syncrip is an RNA-binding protein involved in RNA metabolism, such as RNA stability, splicing, and translational control (24-27). EEF2 (eukaryotic elongation factor 2), as its name indicates, is an essential factor for protein synthesis, promoting the GTP-dependent translocation of the nascent 
Table I. Flightless I-interacting proteins associated with RNA post-transcriptional regulation.

\begin{tabular}{|c|c|c|c|}
\hline Protein IDs & Protein names & Gene names & Function \\
\hline IPI00893918 & Valyl-tRNA synthetase & VARS & Protein translation \\
\hline IPI00001639 & Karyopherin subunit $\beta-1$ & KPNB1 & Protein import into nucleus \\
\hline IPI00001738 & Nuclear pore complex protein Nup88 & NUP88 & RNA translocation \\
\hline IPI00877174 & 2'-5'-oligoadenylate synthase 3 & OAS3 & RNA binding \\
\hline IPI00003704 & RNA-binding protein 4 & RBM4 & RNA binding \\
\hline IPI00644708 & Nucleolysin TIAR & TIAL1 & RNA binding \\
\hline IPI00005675 & $\mathrm{NF}-\kappa-\mathrm{B}-$ repressing factor & NKRF & RNA binding \\
\hline IPI00218187 & $\begin{array}{l}\text { Serine/threonine-protein phosphatase } \\
\text { PP1- } \gamma \text { catalytic subunit }\end{array}$ & PPP1CC & RNA binding \\
\hline IPI00006025 & $\begin{array}{l}\text { Squamous cell carcinoma antigen } \\
\text { recognized by T-cells } 3\end{array}$ & SART3 & mRNA splicing \\
\hline IPI00337397 & Nuclear pore complex protein Nup98 & NUP98 & mRNA export from nucleus \\
\hline IPI00007818 & $\begin{array}{l}\text { Cleavage and polyadenylation specificity } \\
\text { factor subunit } 3\end{array}$ & CPSF3 & mRNA export from nucleus \\
\hline IPI00179713 & Insulin-like growth factor 2 mRNA-binding protein 2 & IMP2 & mRNA transport \\
\hline IPI00010200 & Probable ATP-dependent RNA helicase YTHDC2 & YTHDC2 & RNA processing \\
\hline IPI00010700 & Large proline-rich protein BAT2 & BAT2 & RNA binding \\
\hline IPI00873899 & ATP-binding cassette sub-family F member 1 & ABCF1 & Protein translation \\
\hline IPI00013877 & Heterogeneous nuclear ribonucleoprotein $\mathrm{H} 3$ & HNRNPH3 & RNA splicing, RNA processing \\
\hline IPI00014474 & A-kinase anchor protein 8 & AKAP8 & RNA binding \\
\hline IPI00015952 & Eukaryotic translation initiation factor $4 \gamma$ & EIF4G2 & Translational initiation \\
\hline IPI00016910 & Eukaryotic translation initiation factor 3 subunit $\mathrm{C}$ & EIF3C & Translational initiation \\
\hline IPI00017669 & $\begin{array}{l}\text { SWI/SNF-related matrix-associated actin-dependent } \\
\text { regulator of chromatin subfamily E member } 1\end{array}$ & BAF57 & RNA binding \\
\hline IPI00018120 & $28 \mathrm{~S}$ ribosomal protein $\mathrm{S} 29$ & DAP3 & RNA binding \\
\hline IPI00018140 & Heterogeneous nuclear ribonucleoprotein Q & $\begin{array}{l}\text { HNRPQ } \\
\text { (Syncrip) }\end{array}$ & $\begin{array}{l}\text { RNA splicing, RNA processing, } \\
\text { RNA binding }\end{array}$ \\
\hline IPI00018522 & Protein arginine N-methyltransferase 1 & PRMT1 & RNA binding \\
\hline IPI00019380 & Nuclear cap-binding protein subunit 1 & NCBP1 & $\begin{array}{l}\text { mRNA export from nucleus, RNA } \\
\text { splicing, RNA binding }\end{array}$ \\
\hline IPI00021435 & $26 \mathrm{~S}$ protease regulatory subunit 7 & PSMC2 & Regulation of mRNA stability \\
\hline IPI00926977 & $26 \mathrm{~S}$ protease regulatory subunit $\mathrm{S} 10 \mathrm{~B}$ & PSMC6 & Regulation of mRNA stability \\
\hline IPI00025491 & Eukaryotic initiation factor 4A-I & EIF4A1 & $\begin{array}{l}\text { RNA binding, translational } \\
\text { initiation }\end{array}$ \\
\hline IPI00026665 & Glutaminyl-tRNA synthetase variant & QARS & RNA binding, protein translation \\
\hline IPI00026969 & SEC23-interacting protein & SEC23IP & RNA binding \\
\hline IPI00027107 & Elongation factor $\mathrm{Tu}$ & TUFM & $\begin{array}{l}\text { Translational elongation, RNA } \\
\text { binding }\end{array}$ \\
\hline IPI00027415 & Probable ATP-dependent RNA helicase DHX36 & DHX36 & RNA binding \\
\hline IPI00847793 & Dermcidin isoform 2 & DCD & RNA binding \\
\hline IPI00043407 & Trinucleotide repeat-containing gene $6 \mathrm{C}$ protein & TNRC6C & $\begin{array}{l}\text { Translation regulation, RNA } \\
\text { binding }\end{array}$ \\
\hline IPI00384265 & Constitutive coactivator of PPAR- $\gamma$-like protein 1 & FAM120A & RNA binding \\
\hline IPI00073779 & $28 \mathrm{~S}$ ribosomal protein $\mathrm{S} 35$ & MRPS35 & RNA binding \\
\hline IPI00100151 & 5'-3' exoribonuclease 2 & XRN2 & RNA processing, RNA binding \\
\hline IPI00106567 & WD repeat-containing protein 33 & WDR33 & mRNA processing, RNA binding \\
\hline IPI00141318 & Cytoskeleton-associated protein 4 & CKAP4 & RNA binding \\
\hline IPI00163084 & Pre-mRNA-splicing factor SYF1 & XAB2 & mRNA processing, mRNA splicing \\
\hline IPI00165434 & YLP motif-containing protein 1 & YLPM1 & RNA binding \\
\hline IPI00168885 & Putative ATP-dependent RNA helicase DHX57 & DHX57 & RNA binding, RNA processing \\
\hline IPI00171127 & Ubiquitin-associated protein 2 & UBAP2 & RNA binding \\
\hline
\end{tabular}


Table I. Continued.

\begin{tabular}{|c|c|c|c|}
\hline Protein IDs & Protein names & Gene names & Function \\
\hline IPI00646361 & Nuclear pore complex protein Nup214 & NUP214 & $\begin{array}{l}\text { mRNA export from nucleus, } \\
\text { regulation of mRNA stability }\end{array}$ \\
\hline IPI00220609 & Nucleoporin SEH1-like & SEH1L & mRNA export from nucleus \\
\hline IPI00186290 & Elongation factor 2 & EEF2 & RNA binding \\
\hline IPI00217413 & ATP-dependent RNA helicase DHX29 & DHX29 & RNA binding, RNA processing \\
\hline IPI00217466 & Histone H1c & HIST1H1D & RNA binding \\
\hline IPI00375144 & Serrate RNA effector molecule homolog & SRRT & mRNA splicing, RNA binding \\
\hline IPI00396171 & Microtubule-associated protein 4 & MAP4 & RNA binding \\
\hline IPI00941899 & Pyruvate kinase isozymes M1/M2 & PKM2 & RNA binding \\
\hline IPI00549248 & Nucleophosmin & NPM1 & $\begin{array}{l}\text { RNA binding, regulation of } \\
\text { translation }\end{array}$ \\
\hline IPI00220834 & ATP-dependent DNA helicase 2 subunit 2 & XRCC5 & RNA binding \\
\hline IPI00221106 & Splicing factor 3B subunit 2 & SF3B2 & $\begin{array}{l}\text { mRNA processing, mRNA splicing, } \\
\text { RNA binding }\end{array}$ \\
\hline IPI00291939 & Structural maintenance of chromosomes protein $1 \mathrm{~A}$ & SMC1A & RNA binding \\
\hline IPI00910194 & Nuclear pore complex protein Nup153 & NUP153 & mRNA export from nucleus \\
\hline IPI00294242 & $28 \mathrm{~S}$ ribosomal protein $\mathrm{S} 31$ & MRPS31 & RNA binding \\
\hline IPI00294536 & Serine-threonine kinase receptor-associated protein & STRAP & $\begin{array}{l}\text { mRNA processing, mRNA splicing, } \\
\text { RNA binding }\end{array}$ \\
\hline IPI00296337 & DNA-dependent protein kinase catalytic subunit & PRKDC & RNA binding \\
\hline IPI00646058 & Scaffold attachment factor B & SAFB & $\begin{array}{l}\text { regulation of mRNA processing, } \\
\text { RNA binding }\end{array}$ \\
\hline IPI00304692 & Heterogeneous nuclear ribonucleoprotein $\mathrm{G}$ & RBMX & mRNA processing, mRNA splicing \\
\hline IPI00304925 & Heat shock $70 \mathrm{kDa}$ protein 1 & HSPA1A & regulation of mRNA stability \\
\hline IPI00853598 & Protein SEC13 homolog & SEC13 & mRNA transport \\
\hline IPI00382470 & Heat shock protein HSP $90-\alpha$ & HSP90AA1 & RNA binding \\
\hline IPI00940033 & Trinucleotide repeat-containing gene $6 \mathrm{~B}$ protein & TNRC6B & Translation regulation \\
\hline IPI00396435 & $\begin{array}{l}\text { Putative pre-mRNA-splicing factor ATP-dependent } \\
\text { RNA helicase DHX15 }\end{array}$ & DHX15 & mRNA processing, mRNA splicing \\
\hline IPI00396485 & Elongation factor $1-\alpha 1$ & EEF1A1 & translational elongation \\
\hline IPI00418497 & $\begin{array}{l}\text { Mitochondrial import inner membrane translocase } \\
\text { subunit TIM50 }\end{array}$ & TIMM50 & RNA binding \\
\hline IPI00453473 & Histone H4 & HIST1H4A & RNA binding \\
\hline IPI00455134 & Heterogeneous nuclear ribonucleoprotein A3 & HNRNPA3 & $\begin{array}{l}\text { mRNA processing, mRNA splicing, } \\
\text { RNA binding, mRNA transport }\end{array}$ \\
\hline IPI00644127 & Isoleucyl-tRNA synthetase & IARS & protein translation \\
\hline IPI00647635 & $\begin{array}{l}\text { PERQ amino acid-rich with GYF domain-containing } \\
\text { protein } 2\end{array}$ & GIGYF2 & $\begin{array}{l}\text { RNA binding, regulation of } \\
\text { translation }\end{array}$ \\
\hline IPI00784224 & Zinc finger RNA-binding protein & ZFR & RNA binding \\
\hline IPI00783872 & Caprin-1 & CAPRIN1 & RNA binding \\
\hline IPI00871240 & Protein SCAF8 & RBM16 & mRNA processing, mRNA splicing \\
\hline
\end{tabular}

peptide from the A-site to the P-site of ribosome during the translational process (28).

Construction and functional enrichment analysis of the protein interaction network involving FLII and its interactors. The biological functions of all putative FLII binders were then categorized by consulting the genecards databases, we found that more than a half (74 out of the 132 total) of the putative
FLII interactors are associated with RNA post-transcriptional modifications, RNA and protein nucleocytoplasmic transport and protein biosynthesis (Table I). To further assess the relevance of this result and to identify the biological processes and signaling pathways involving FLII and its interacting proteins, we used STRING program to build a protein interaction network comprising these putative interactors (not shown due to the impossibility of exporting a figure which could meet the 
Table II. Functional enrichments in Flightless I-interacting network.

\begin{tabular}{|c|c|c|c|}
\hline Pathway ID & Pathway description & Count in gene set & False discovery rate \\
\hline \multicolumn{4}{|c|}{ Biological process (GO) } \\
\hline GO:0010467 & Gene expression & 61 & $7.44 \mathrm{e}-10$ \\
\hline GO:0006807 & Nitrogen compound metabolic process & 68 & $1.16 \mathrm{e}-07$ \\
\hline GO:0034641 & Cellular nitrogen compound metabolic process & 65 & $1.57 \mathrm{e}-07$ \\
\hline GO:0010033 & Response to organic substance & 41 & $9.68 \mathrm{e}-07$ \\
\hline GO:0043170 & Macromolecule metabolic process & 77 & $9.68 \mathrm{e}-07$ \\
\hline \multicolumn{4}{|c|}{ Molecular function (GO) } \\
\hline GO:0044822 & poly(A) RNA binding & 54 & $9.17 \mathrm{e}-30$ \\
\hline GO:0003723 & RNA binding & 57 & $4.45 \mathrm{e}-27$ \\
\hline GO:0003676 & Nucleic acid binding & 56 & $1.66 \mathrm{e}-08$ \\
\hline GO:0000166 & Nucleotide binding & 42 & $6.87 \mathrm{e}-08$ \\
\hline GO:0036094 & Small molecule binding & 43 & $4.56 \mathrm{e}-07$ \\
\hline \multicolumn{4}{|c|}{ Cellular component (GO) } \\
\hline GO:0031981 & Nuclear lumen & 68 & $1.16 \mathrm{e}-18$ \\
\hline GO:0005654 & Nucleoplasm & 62 & $1.89 \mathrm{e}-18$ \\
\hline GO:0044428 & Nuclear part & 70 & $1.89 \mathrm{e}-18$ \\
\hline GO:0070013 & Intracellular organelle lumen & 72 & $9.78 \mathrm{e}-12$ \\
\hline GO:0005634 & Nucleus & 84 & $2.02 \mathrm{e}-12$ \\
\hline \multicolumn{4}{|l|}{ KEGG pathways } \\
\hline 03013 & RNA transport & 12 & $8.61 \mathrm{e}-08$ \\
\hline 03040 & Spliceosome & 8 & 0.000217 \\
\hline 04141 & Protein processing in endoplasmic reticulum & 7 & 0.00885 \\
\hline 03015 & mRNA surveillance pathway & 5 & 0.0177 \\
\hline \multicolumn{4}{|c|}{ PFAM protein domains } \\
\hline PF00076 & $\begin{array}{l}\text { RNA recognition motif. (a.k.a. RRM, RBD, } \\
\text { or RNP domain) }\end{array}$ & 7 & 0.0306 \\
\hline PF03144 & Elongation factor Tu domain 2 & 3 & 0.0466 \\
\hline
\end{tabular}

publication standard). Among the total 133 proteins analyzed (nodes), 115 are connected with at least one other partner by at least one kind of interactions (edges). An important number of nodes are connected with its partner(s) by multiple edges. For the 133 nodes analyzed, the number of edges was 305 , significantly superior to the expected value that is 164 , resulting in an average node degree of 4.59, a clustering coefficient of 0.539 , and a PPI enrichment P-value of 0 . These network statistics clearly demonstrate that this protein interaction network has significantly more interactions than expected, and is therefore statistically reliable and functionally relevant. The functional enrichments in this network were determined according to biological process, molecular function, cellular component, KEGG pathways and PFAM protein domains (Table II). As expected, the results clearly indicate that the interactome of FLII is associated with RNA post-transcriptional regulations and functions, with the top ranked biological process being the gene expression, and the top molecular functions being the RNA/nucleic acid binding, supported by the top ranked KEGG pathways as RNA transport, spliceosome, protein processing and mRNA surveillance (Table II). These results, which depict a comprehensive interactome of FLII in H1299 cells, suggest strongly that FLII might play a role in the post-transcriptional regulation and function of RNA through interactions with the RNA-binding proteins and nucleoporins.

Assessment of FLII functions in RNA trafficking and translation by high throughput sequencing. The nature of the FLII binders identified by us strongly pointed to an involvement of FLII in RNA post-transcriptional modification and trafficking in lung adenocarcinoma H1299 cells, we strived to verify this hypothesis. We have stably knocked down FLII in HBE cells by using a lentiviral shRNA vector, and in parallel, overexpressed Flag-FLII in H1299 cells by transient transfection. The effectiveness of the knockdown and overexpression of FLII respectively in HBE and H1299 cells was confirmed by both western blotting using anti-FLII and anti-Flag antibodies (Fig. 4A), and by qPCR (Fig. 3B). Furthermore, Boyden chamber assays were performed to confirm the functional impact of the alteration of FLII expression in these cells. As shown in Fig. 3C and D, FLII knockdown in HBE cells considerably stimulated their migration and invasion, whereas FLII overexpression showed inhibition ability. 
A

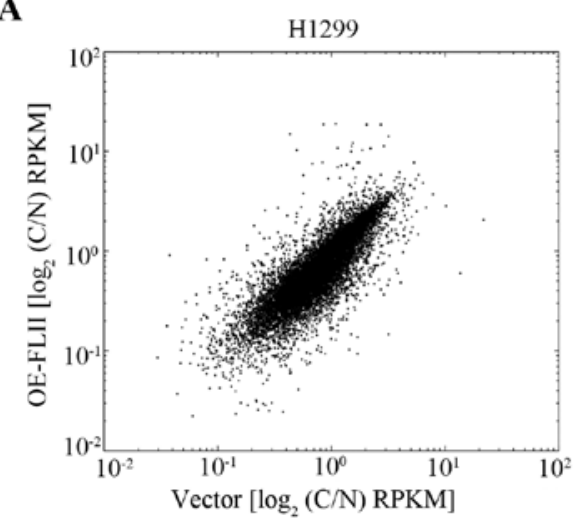

C

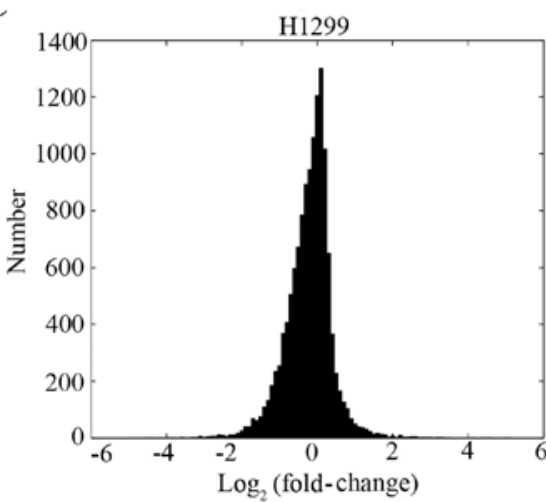

$\mathbf{E}$

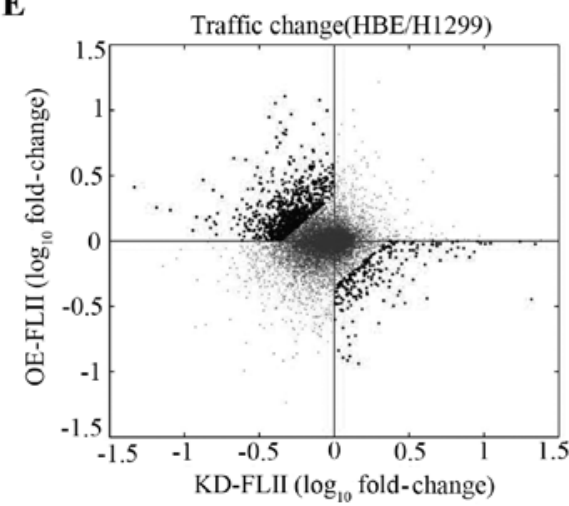

B

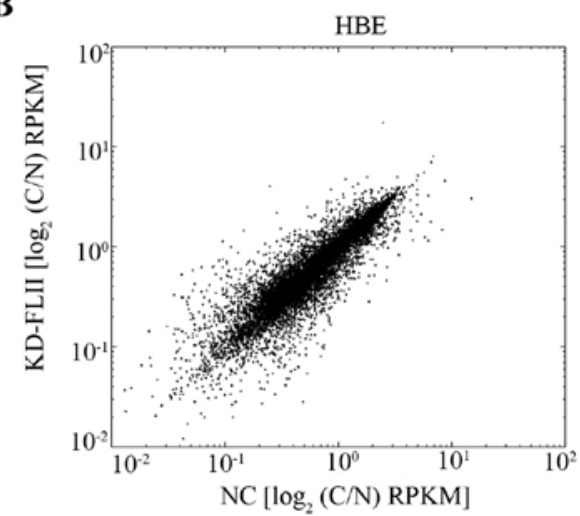

D

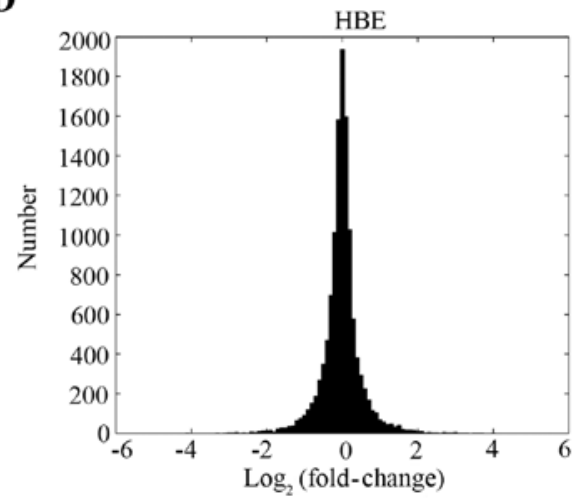

Figure 5. Assessment of FLII functions in nucleocytoplasmic trafficking of mRNA by high throughput sequencing. The variation of the cytoplasm/nucleus ratio of each mRNA (represented by a corresponding gray dot in the diagram) in FLII-overexpressing H1299 (A) or FLII-knocked down HBE cells (B). The cytoplasm/nucleus ratio of each mRNA in FLII-overexpressing or FLII-knocked down cells were plotted versus their respective controls (Vector or NC, as indicated). (C and D) The distribution in fold changes of the FLII regulated mRNA in the corresponding cells used in (A and B). (E) Changes of mRNA cytoplasm/nucleus ratio caused by FLII-overexpressing in H1299 cells versus those caused by FLII- knocked down in HBE cells. The black dots in the second and fourth quadrants represent the mRNA whose cytoplasm/nucleus distribution ratios are regulated by FLII.

High throughput sequencing was then used to assess the role of FLII in the overall biosynthesis and metabolism of the mRNA. We checked the effect of FLII knockdown and overexpression on the overall transcription of the genes. Total mRNA for both FLII knocked down HBE cells and H1299 cells overexpressing FLII, together with their corresponding control cells (respectively the empty vector-transfected and control virus-infected cells), were extracted and reverse transcribed into cDNA. High throughput sequencing was then performed to determine the mRNA species and levels in the various cells. Approximately 14,000 genes were quantified. As shown in Fig. 4, no significant effect of FLII knockdown or overexpression could be observed on the level of total
mRNA levels in HBE or H1299 cells, suggesting that FLII does not affect the overall transcription of genes.

We then evaluated the impact of FLII knockdown or overexpression on the nucleocytoplasmic distribution of mRNA to investigate the possible role of FLII in the nucleocytoplasmic trafficking of mRNA. Cell fractionation experiments were performed with FLII knocked down HBE cells, FLII overexpressing H1299 cells, and the corresponding control cells described above, and the cytoplasmic and nuclear mRNA of each type of cells were separately extracted and subjected to high-throughput sequencing. The variations of the cytoplasmic and nuclear mRNA levels in FLII knockdown or overexpression cells versus their control cells for each gene 
A

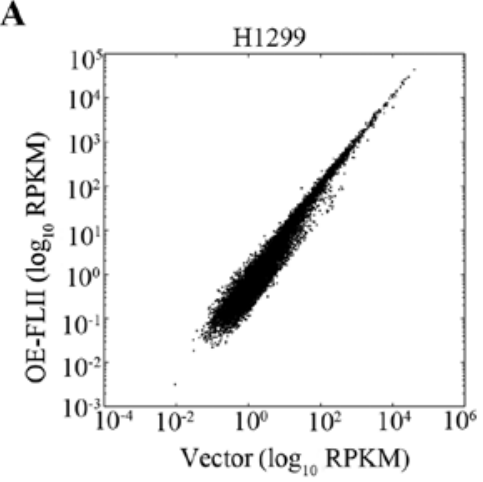

C

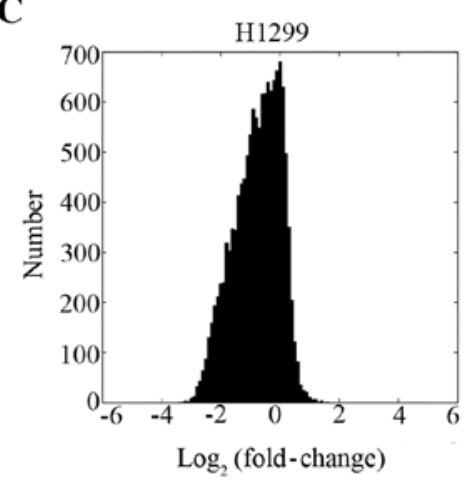

$\mathbf{E}$

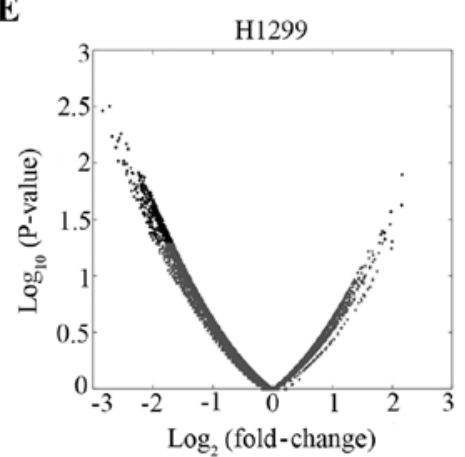

B

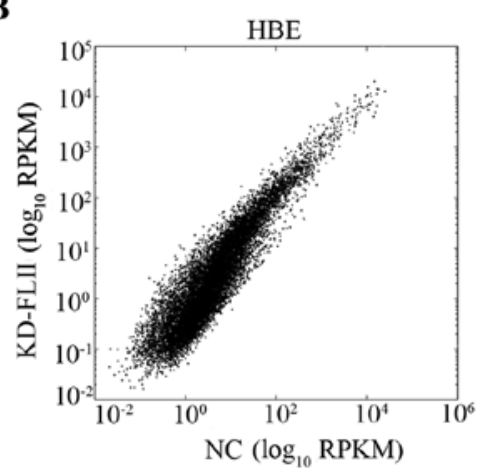

D

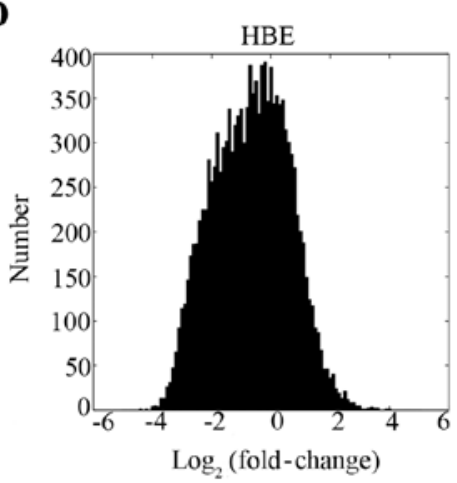

G

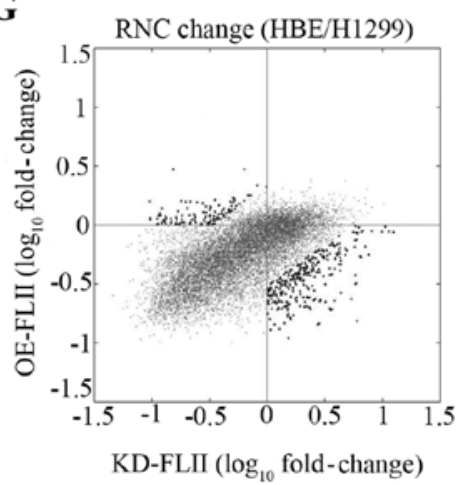

$\mathbf{F}$

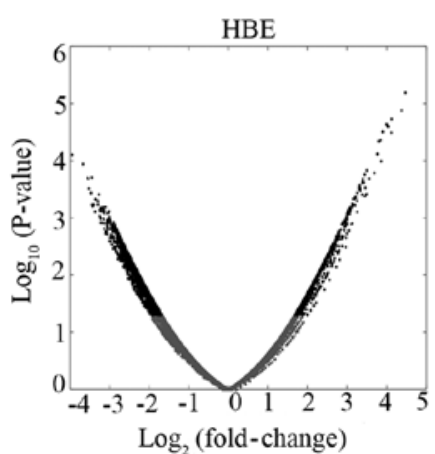

Figure 6. Assessment of FLII function in translation by high throughput sequencing. The variation of RNC-bound mRNA levels in FLII-overexpressing H1299 cells (A), or FLII knocked down HBE cells (B), and the corresponding distributions in fold changes (C and D). (E and F) EdgeR analysis for the differential RNC mRNA levels caused by FLII-overexpression in H1299 cells or FLII knockdown HBE cells. (G) Changes of RNC mRNA levels caused by FLII-overexpressing in H1299 cells versus those caused by FLII knockdown in HBE cells. The black dots in the second and fourth quadrants represent the RNC-bound mRNA whose levels are regulated by FLII. EdgeR analysis for the differential RNC-mRNA levels caused by FLII-overexpression (G), or FLII knockdown (F). Significantly altered genes are denoted by the black dots.

were analyzed as described in Materials and methods. Our results showed that both FLII overexpression in H1299 cells and its knockdown in HBE cells significantly affected the general nuclear-cytoplasmic distribution of mRNA (Fig. 6A-D). These two sets of data were then challenged against each other to compare the quantitative variation of mRNA for each single gene in the two experimental conditions (Fig. 5E). Among all genes whose nucleocytoplasmic distribution was affected by FLII overexpression or FLII knockdown, we considered as relevant those on which FLII knockdown and overexpression significantly exerted opposite effects, that is, either their level was significantly increased by FLII knockdown and decreased by FLII overexpression, or vice versa (Fig. 5E, black spots in the second and fourth quadrants). By this method, we eliminated the bias introduced by the transfection and infection systems we used in this study.

In order to examine the role of FLII on the translational process of mRNA, ribosome-nascent chain complexassociated mRNAs (RNC-mRNAs) from the same cells used for the studies described above were extracted and similarly quantified. Translatome sequencing has quantified over 12,000 genes in translating mRNA. Contrary to the results of the total mRNA levels, we found that FLII knockdown and overexpression significantly affected the level of RNC-mRNAs. Similarly as described above, we have compared the effect of FLII knockdown and overexpression on each gene analyzed and selected as potential FLII target genes those on which FLII knockdown and overexpression significantly exerted opposite effects (Fig. 6E, black spots in 
Table III. Functional categorization of Flightless I-regulated genes.

Top diseases and bio-functions

\begin{tabular}{|c|c|c|}
\hline Name & P-value & \# Molecules \\
\hline \multicolumn{3}{|l|}{ Diseases and disorders } \\
\hline Dermatological diseases and conditions & 2.28E-02-7.41E-08 & 55 \\
\hline Organismal injury and abnormalities & 2.68E-02-7.41E-08 & 337 \\
\hline Cancer & $2.68 \mathrm{E}-02-3.48 \mathrm{E}-06$ & 329 \\
\hline Reproductive system disease & $2.28 \mathrm{E}-02-3.48 \mathrm{E}-06$ & 142 \\
\hline Endocrine system disorders & $2.28 \mathrm{E}-02-5.20 \mathrm{E}-06$ & 112 \\
\hline \multicolumn{3}{|l|}{ Molecular and cellular functions } \\
\hline Cellular movement & $2.45 \mathrm{E}-02-1.42 \mathrm{E}-08$ & 80 \\
\hline Cellular growth and proliferation & 2.73E-02-3.30E-07 & 112 \\
\hline Cell-to-cell signaling and interaction & 2.85E-02-8.30E-06 & 66 \\
\hline Cell morphology & $1.94 \mathrm{E}-02-2.46 \mathrm{E}-05$ & 39 \\
\hline Cellular development & $2.73 \mathrm{E}-02-2.46 \mathrm{E}-05$ & 99 \\
\hline \multicolumn{3}{|l|}{ Physiological system development and function } \\
\hline Cardiovascular system development and function & $2.71 \mathrm{E}-02-2.06 \mathrm{E}-06$ & 33 \\
\hline Organismal development & 2.71E-02-2.06E-06 & 49 \\
\hline Tissue development & 2.73E-02-2.46E-05 & 56 \\
\hline Connective tissue development and function & 2.71E-02-1.15E-04 & 22 \\
\hline Nervous system development and function & 2.73E-02-1.09E-03 & 12 \\
\hline
\end{tabular}

Top networks

\begin{tabular}{lll}
\hline ID & \multicolumn{1}{c}{ Associated network functions } & Score \\
\hline 1 & Cellular movement, cellular growth and proliferation, cell morphology & 40 \\
2 & Cellular development, cellular growth and proliferation, cellular function and maintenance & 38 \\
3 & Cellular movement, hematological system development and function, immune cell trafficking & 34 \\
4 & Cellular movement, organismal injury and abnormalities, reproductive system disease & 24 \\
5 & Cancer, organismal injury and abnormalities, reproductive system disease & 19 \\
\hline
\end{tabular}

Top canonical pathways

\begin{tabular}{llr}
\hline Name & P-value & Overlap \\
\hline IL-12 signaling and production in macrophages & $1.08 \mathrm{E}-04$ & $7.6 \%, 11 / 144$ \\
VDR/RXR activation & $1.14 \mathrm{E}-04$ & $10.4 \%, 8 / 77$ \\
Axonal guidance signaling & $3.68 \mathrm{E}-04$ & $4.5 \%, 20 / 441$ \\
Production of nitric oxide and reactive oxygen species in macrophages & $1.26 \mathrm{E}-03$ & $5.7 \%, 11 / 192$ \\
LPS/IL-1 mediated inhibition of RXR function & $2.37 \mathrm{E}-03$ & $5.3 \%, 11 / 208$ \\
\hline
\end{tabular}

Top upstream regulators

\begin{tabular}{lcc}
\hline Upstream regulator & P-value of overlap & False discovery rate \\
\hline ESR1 & $4.94 \mathrm{E}-06$ & \\
Estrogen receptor & $6.22 \mathrm{E}-05$ & Activated \\
PDGF BB & $7.15 \mathrm{E}-05$ & \\
TNF & $9.44 \mathrm{E}-05$ & Activated \\
SMARCA4 & $1.49 \mathrm{E}-04$ & \\
\hline
\end{tabular}


Table III. Continued.

Top regulator effect networks

\begin{tabular}{|c|c|c|c|}
\hline ID & Regulators & Diseases and functions & Consistency score \\
\hline 1 & NF-кB (complex) & Differentiation of cells ( +1 more) & 3.13 \\
\hline 2 & TGFB1 & Cell movement & -6.935 \\
\hline 3 & $\mathrm{NF}-\kappa \mathrm{B}$ (complex) & Proliferation of cells & -7.906 \\
\hline 4 & ERBB2 & Invasion of tumor cell lines & -12.522 \\
\hline 5 & PDGF BB & Cell proliferation of tumor cell lines & -15.497 \\
\hline
\end{tabular}

the second and fourth quadrants). As indicated, for $4 \%$ of the genes analyzed, the transcription was upregulated by FLII overexpression and downregulated by its knockdown, whereas for another $9.5 \%$, the transcription was inversely regulated by FLII. These genes were then submitted to IPA program to assess their possible involvement in various biological processes and signaling pathways. Table III shows the top ranked diseases and biological functions, top networks and canonical pathways, upstream regulators, and the top regulator effect networks. As shown, the top ranked molecular and cellular functions are cellular movement and cellular growth and proliferation, and the top diseases and disorders associated with FLII regulated genes are dermatological diseases and conditions, organismal injury and abnormalities, and cancer. The top canonical pathways revealed to be the IL-12 signaling and production in macrophages and the VDR/RXR activation, whereas the top upstream regulator is estrogen receptor 1 , and the top regulator effector network is $\mathrm{NF}-\kappa \mathrm{B}$. Taken together, these results suggest that FLII might be involved in the determination of the cell fate, the regulation of development, the injury repair, the immune response and cancer by controlling the mRNA metabolism and trafficking of several groups of genes.

\section{Discussion}

Growing evidence indicates that FLII plays important roles in multiple cellular processes $(8,9,29)$. The characteristic feature of FLII being composed by two protein-protein interaction domains suggests that protein interactions might be key elements of the mechanisms governing its versatile functions. However, little has been done with success in the past to specifically and systematically identify the interacting partners of this protein. Two yeast two-hybrid screenings, respectively reported by Liu and Yin in 1998 (15), and by Fong and de Couet in 1999 (16), have led to the identification of three homologous proteins as the interactors of FLII LRR domain, referred to as LRRFIP1 and LRRFIP2 (LRR FLII interacting protein 1 and 2) and FLAP (FLII associating protein). Unfortunately, neither study was able to depict, at the systemic level, the whole interactome of FLII, because all [4 clones, (15)] or most [12 from the 18, (16)] of the positive clones from these two screenings were derived from the genes encoding these three proteins. Besides, a few other proteins have also been independently reported to bind FLII in various contexts and with diverse functions, such as actin, BAF53,
CARM1, ChREBP and Rac1 (10,15,30-34). In this study, by combining immunoprecipitation and mass spectrometry analysis, we successfully identified 132 FLII interacting proteins and constructed the first putative interaction network of FLII in the cell. Interestingly, our data displayed striking directivity, in that more than a half of these candidate interactors are associated with RNA post-transcriptional regulation such as splicing, maturation, trafficking and protein synthesis (Table II). These results strongly suggested an undiscovered function of FLII in the regulation of RNA metabolism.

The target genes of FLII that we identified by using the RNC-bound RNA sequencing and IPA analysis encode mainly the proteins involved in the cellular processes such as cellular movement, cellular growth and proliferation, and the development at cellular, tissue, and organismal levels. They are also associated with the diseases and disorders such as dermatological diseases and conditions, organismal injury and abnormalities, and cancer. Moreover, the top ranked canonical pathways identified are IL-12 signaling and production in macrophages and VDR/RXR activation. These physiological and pathological processes and functions are very reminiscent of the reported functions of FLII, that are embryonic development, the regulation of wound repair, skin barrier development, the recovery after blistering and regulation of immune response, and more recently cancer (2-13). This confirmed, on one hand, the reliability of our approaches and the authenticity of our results, and on the other hand, suggested a novel mechanism of action of FLII, that is the overall posttranscriptional regulation of mRNA.

We find that FLII knockdown or overexpression affects at the same time the nucleus/cytoplasm ratio of mRNA and the RNC-bound mRNA amounts and species. The result of FLII interactome suggest that FLII might bind to both the proteins involved in the mRNA post-transcriptional modifications and translation, and those involved in mRNA trafficking, such as the nucleoporins. However, it remains to be determined whether FLII is involved in both the trafficking and the translational regulation of mRNA, or just play a role in mRNA trafficking which might impact on the subsequent translational process. No known RNA-binding domain has been found on FLII protein, which suggests that its function in the regulation of RNA trafficking or/and post-transcriptional regulation might be mediated by its interactions with numerous proteins involved in these biological processes. FLII might take part in the protein complexes associated with mRNA, and exerts its functions through direct and indirect 
interactions with various partners regulating one or several steps of mRNA post-transcriptional modification, trafficking and metabolism. For example, its interaction with Nup88 and Nup214 might be involved in the nuclear export of mRNP complexes since Nup214-Nup88 nucleoporin subcomplex has been shown to play an important role in the nuclear export of the mRNA and protein complexes (35-38). Particularly, Nup214-Nup88 complex is required for the CRM1-mediated nuclear export of the 60S preribosomal subunit (36), hinting to the possible impact on the overall translation of mRNA. On the other hand, the interactions of FLII with the proteins playing roles in the translational regulation such as TIAL1 might also be functionally relevant. TIAL1, also named TIAR, was found to bind several mRNAs encoding translation factors such as eukaryotic initiation factor 4A (eIF4A) and eIF4E (translation initiation factors), eEF2 (a translation elongation factor), and c-Myc (which transcriptionally controls the expression of numerous translation regulatory proteins), suppressing their translation and participating to the global inhibition of translation machinery in response to low levels of short-wavelength UV irradiation (39). FLII possibly exerts its regulatory functions by interacting with these RNA-binding proteins through its N-terminal LRR domain, and with actin cytoskeleton via its C-terminal gelsolin related repeats, thereby mediating the traffic of the mRNP complexes along the actin filaments, and modulating the translational processes. In support of this hypothesis, we have been able to detect the interaction of the FLII LRR domain with Nup88 by in vitro GST pull-down assay (data not shown).

Guided by the results of FLII interactome obtained in this study, further studies allowing the confirmation and functional demonstration of these relevant interactions will provide new elements for the comprehensive understanding of the precise mechanisms of action of FLII.

\section{Acknowledgements}

This work was partially supported by National Program on Key BasicResearch Project(973 Program)(grantno.2011CB910700); Natural Science Foundation of China (grant no. 81322028); Natural Science Foundation of Guangdong Province (grant no. 2016A030313083; 2016A030313420); Guangzhou Science and Technology Project (20160701175); Fundamental Research Funds for the Central Universities (grant no. 21615407; 21609317); Science and Technology Program of Huadu District of Guangzhou, Guangdong Province (15-HDWS-016).

\section{References}

1. She J, Yang P, Hong Q and Bai C: Lung cancer in China: Challenges and interventions. Chest 143: 1117-1126, 2013.

2. Campbell HD, Schimansky T, Claudianos C, Ozsarac N, Kasprzak AB, Cotsell JN, Young IG, de Couet HG and Miklos GL: The Drosophila melanogaster flightless-I gene involved in gastrulation and muscle degeneration encodes gelsolin-like and leucine-rich repeat domains and is conserved in Caenorhabditis elegans and humans. Proc Natl Acad Sci USA 90: 11386-11390, 1993.

3. Campbell HD, Fountain S, Young IG, Claudianos C, Hoheisel JD, Chen K-S and Lupski JR: Genomic structure, evolution, and expression of human FLII, a gelsolin and leucine-rich-repeat family member: Overlap with LLGL. Genomics 42: 46-54, 1997.
4. Davy DA, Ball EE, Matthaei KI, Campbell HD and Crouch MF: The flightless I protein localizes to actin-based structures during embryonic development. Immunol Cell Biol 78: 423-429, 2000.

5. Campbell HD, Fountain S, McLennan IS, Berven LA, Crouch MF, Davy DA, Hooper JA, Waterford K, Chen K-S, Lupski JR, et al: Fliih, a gelsolin-related cytoskeletal regulator essential for early mammalian embryonic development. Mol Cell Biol 22: 3518-3526, 2002.

6. Wang T, Chuang T-H, Ronni T, Gu S, Du Y-C, Cai H, Sun H-Q, Yin HL and Chen X: Flightless I homolog negatively modulates the TLR pathway. J Immunol 176: 1355-1362, 2006.

7. Cowin AJ, Adams DH, Strudwick XL, Chan H, Hooper JA, Sander GR, Rayner TE, Matthaei KI, Powell BC and Campbell HD: Flightless I deficiency enhances wound repair by increasing cell migration and proliferation. J Pathol 211: 572-581, 2007.

8. Li J, Yin HL and Yuan J: Flightless-I regulates proinflammatory caspases by selectively modulating intracellular localization and caspase activity. J Cell Biol 181: 321-333, 2008.

9. Kopecki Z, Yang GN, Arkell RM, Jackson JE, Melville E, Iwata H, Ludwig RJ, Zillikens D, Murrell DF and Cowin AJ: Flightless I over-expression impairs skin barrier development, function and recovery following skin blistering. J Pathol 232: 541-552, 2014.

10. Wu L, Chen H, Zhu Y, Meng J, Li Y, Li M, Yang D, Zhang P, Feng $\mathrm{M}$ and Tong $\mathrm{X}$ : Flightless I homolog negatively regulates ChREBP activity in cancer cells. Int J Biochem Cell Biol 45: 2688-2697, 2013

11. Jeong KW: Flightless I (Drosophila) homolog facilitates chromatin accessibility of the estrogen receptor $\alpha$ target genes in MCF-7 breast cancer cells. Biochem Biophys Res Commun 446: 608-613, 2014

12. Kopecki Z, Yang GN, Jackson JE, Melville EL, Calley MP, Murrell DF, Darby IA, O'Toole EA, Samuel MS and Cowin AJ: Cytoskeletal protein Flightless I inhibits apoptosis, enhances tumor cell invasion and promotes cutaneous squamous cell carcinoma progression. Oncotarget 6: 36426-36440, 2015.

13. Wang T, Song W, Chen Y, Chen R, Liu Z, Wu L, Li M, Yang J, Wang L, Liu J, et al: Flightless I homolog represses prostate cancer progression through targeting androgen receptor signaling. Clin Cancer Res 22: 1531-1544, 2016.

14. Stone L: Bladder cancer: In the driving seat - AGL loss drives tumour growth. Nat Rev Urol 13: 3-3, 2016.

15. Liu Y-T and Yin HL: Identification of the binding partners for flightless I, A novel protein bridging the leucine-rich repeat and the gelsolin superfamilies. J Biol Chem 273: 7920-7927, 1998.

16. Fong KS and de Couet HG: Novel proteins interacting with the leucine-rich repeat domain of human flightless-I identified by the yeast two-hybrid system. Genomics 58: 146-157, 1999.

17. Luo W, Slebos RJ, Hill S, Li M, Brábek J, Amanchy R, Chaerkady R, Pandey A, Ham A-JL and Hanks SK: Global impact of oncogenic Src on a phosphotyrosine proteome. J Proteome Res 7: 3447-3460, 2008

18. Esposito AM, Mateyak M, He D, Lewis M, Sasikumar AN Hutton J, Copeland PR and Kinzy TG: Eukaryotic polyribosome profile analysis. J Vis Exp pii: 1948, 2010. doi: 10.3791/1948.

19. Rajkumar AP, Qvist P, Lazarus R, Lescai F, Ju J, Nyegaard M, Mors O, Børglum AD, Li Q and Christensen JH: Experimental validation of methods for differential gene expression analysis and sample pooling in RNA-seq. BMC Genomics 16: 548, 2015.

20. Huang Q, Gumireddy K, Schrier M, le Sage C, Nagel R, Nair S, Egan DA, Li A, Huang G, Klein-Szanto AJ, et al: The microRNAs miR-373 and miR-520 c promote tumour invasion and metastasis. Nat Cell Biol 10: 202-210, 2008.

21. Ström A-C and Weis K: Importin-beta-like nuclear transport receptors. Genome Biol 2: S3008, 2001.

22. Yi R, Qin Y, Macara IG and Cullen BR: Exportin-5 mediates the nuclear export of pre-microRNAs and short hairpin RNAs. Genes Dev 17: 3011-3016, 2003.

23. Hutten S and Kehlenbach RH: Nup214 is required for CRM1dependent nuclear protein export in vivo. Mol Cell Biol 26: 6772-6785, 2006.

24. Vincendeau M, Nagel D, Brenke JK, Brack-Werner R and Hadian K: Heterogenous nuclear ribonucleoprotein Q increases protein expression from HIV-1 Rev-dependent transcripts. Virol J 10: 151, 2013.

25. Svitkin YV, Yanagiya A, Karetnikov AE, Alain T, Fabian MR, Khoutorsky A, Perreault S, Topisirovic I and Sonenberg N: Control of translation and miRNA-dependent repression by a novel poly(A) binding protein, hnRNP-Q. PLoS Biol 11: e1001564, 2013. 
26. Shimizu Y, Nishitsuji H, Marusawa H, Ujino S, Takaku H and Shimotohno K: The RNA-editing enzyme APOBEC1 requires heterogeneous nuclear ribonucleoprotein $\mathrm{Q}$ isoform 6 for efficient interaction with interleukin-8 mRNA. J Biol Chem 289: 26226-26238, 2014.

27. Beuck C, Williamson JR, Wüthrich K and Serrano P: The acidic domain is a unique structural feature of the splicing factor SYNCRIP. Protein Sci 25: 1545-1550, 2016.

28. Kaul G, Pattan G and Rafeequi T: Eukaryotic elongation factor-2 (eEF2): Its regulation and peptide chain elongation. Cell Biochem Funct 29: 227-234, 2011.

29. Kopecki $Z$ and Cowin AJ: Flightless I: An actin-remodelling protein and an important negative regulator of wound repair. Int J Biochem Cell Biol 40: 1415-1419, 2008.

30. Lee Y-H, Campbell HD and Stallcup MR: Developmentally essential protein flightless $\mathrm{I}$ is a nuclear receptor coactivator with actin binding activity. Mol Cell Biol 24: 2103-2117, 2004.

31. Archer S, Behm C, Hooper J, Judge R, Matthaei K, Powell B, Cowin A and Campbell $\mathrm{H}$ : A novel, evolutionarily conserved role in intracellular signalling for the gelsolin-related actin-binding protein Flightless I. The FEBS Journal 272: 282, 2005.

32. Orloff $G$, Allen P, Miklos G, Young I, Campbell $H$ and Kwiatkowski D: Human flightless-I has actin-binding ability. Molecular Biology of the Cell 6: 803, 1995.
33. Jeong KW, Lee Y-H and Stallcup MR: Recruitment of the SWI/SNF chromatin remodeling complex to steroid hormoneregulated promoters by nuclear receptor coactivator flightless-I. J Biol Chem 284: 29298-29309, 2009.

34. Marei H, Carpy A, Woroniuk A, Vennin C, White G, Timpson P, Macek B and Malliri A: Differential Rac1 signalling by guanine nucleotide exchange factors implicates FLII in regulating Rac1driven cell migration. Nat Commun 7: 10664, 2016.

35. van Deursen J, Boer J, Kasper L and Grosveld G: G2 arrest and impaired nucleocytoplasmic transport in mouse embryos lacking the proto-oncogene CAN/Nup214. EMBO J 15: 55745583, 1996.

36. Bernad R, Engelsma D, Sanderson H, Pickersgill H and Fornerod M: Nup214-Nup88 nucleoporin subcomplex is required for CRM1-mediated $60 \mathrm{~S}$ preribosomal nuclear export. J Biol Chem 281: 19378-19386, 2006.

37. Carmody SR and Wente SR: mRNA nuclear export at a glance. J Cell Sci 122: 1933-1937, 2009.

38. Simon DN and Rout MP: Cancer and the nuclear pore complex. In: Cancer Biology and the Nuclear Envelope. Schirmer EC and de las Heras JI (eds). Springer, New York, pp285-307, 2014.

39. Mazan-Mamczarz K, Lal A, Martindale JL, Kawai T and Gorospe M: Translational repression by RNA-binding protein TIAR. Mol Cell Biol 26: 2716-2727, 2006. 